\title{
Development of Symbiotic Double Microencapsulation Technique for Efficient Delivery of Probiotics
}

\author{
Shilpa Sabnis* and Nikita Malavkar \\ Department of Microbiology, The Institute of Science, Mumbai-400 032, India \\ *Corresponding author
}

\begin{abstract}
A B S T R A C T
Keywords

Probiotic,

Micro-

encapsulation,

Sodium Alginate,

Chitosan,

Gastric Juice, Intestinal Juice.

Article Info

Accepted:

15 March 2016

Available Online:

10 April 2016

The use of probiotic bacteria in novel foods to provide beneficial health effects is gaining interest in the food industry. Microencapsulation technology can be used to maintain the viability of probiotic bacteria during food product processing and storage. The present study was an attempt to develop efficient symbiotic microencapsulation method for increased stability and viability of probiotics under refrigerated storage as well as simulated gastrointestinal conditions to confer health benefits to the host using sodium alginate and chitosan as coating biomaterial using extrusion technique. A comparative study between free and encapsulated cells with respect to their viability and stability under these conditions was carried out. The encapsulated cells showed a higher viability compared to free cells on storage at $4^{\circ} \mathrm{C}$ for 7 days. Encapsulated probiotics also showed an improved percentage survival in Simulated Gastric Juice ( $\mathrm{pH} 2$ ) and Simulated Intestinal Juice ( $\mathrm{pH}$ 8). Microencapsulation of probiotics offers an effective way of delivering viable bacterial cells to the digestive tract and maintaining their survival during refrigerated storage.
\end{abstract}

\section{Introduction}

Probiotics are defined as live microorganisms which when administered in adequate amounts confer health benefits to host (WHO report as cited in Michael de Vrese, 2009). Probiotic bacteria are becoming increasingly popular as food cultures, in parallel with an increased awareness of their contribution to good health. Health advantages associated with the probiotic intake include alleviation of symptoms of lactose malabsorption, increase in natural resistance to infectious diseases of the intestinal tract, suppression of cancer, reduction in serum cholesterol concentrations, improved digestion, and stimulation of gastrointestinal immunity (Iyer and Kailasapathy, 2005; Kailasapathy and Chin, 2000).

Mixture of pro- and probiotics is symbiotic which beneficially affects the host by improving the survival and implementation 
of live microbial dietary supplements in the gastrointestinal tract by selectively stimulating the growth and/or by activating the metabolism of health promoting bacteria and thus improving host welfare. According to this approach, a food or food supplement will include both the live cells of the beneficial bacteria and a selective substrate; the idea being that the beneficial bacterial cells that survive their transit through the stomach can grow quickly and competitively because of the presence of the selective substrate and establish their predominance (Babu et al., 2011).

Lactic acid bacteria (LAB) have attained major attention for probiotic activity and have generally been considered as good probiotic organisms (Ashraf et al., 2009). Probiotic LAB are often found naturally in foodstuffs such as milk, meat and vegetables (Setyawardani et al., 2011). It is generally accepted that successful delivery and colonization of viable probiotic cells in the intestine are essential for probiotics to be efficacious. Lactic Acid Bacteria (LAB) in foods and food supplements are considered commensal microorganisms with no pathogenic potential. Their unique presence in intestinal epithelium and human gastrointestinal tract, and their traditional use in fermented foods and dairy products without remarkable problems prove their safety (Jafari et al., 2011). As a guide, the International Dairy Federation has recommended that the bacteria be viable and abundant in the product and be present at a population of at least $10^{7}$ colony-forming units (CFU)/g until the date of consumption (Kosin and Rakshit, 2006; Kailasapathy and Chin, 2000; Lapsiri et al., 2011). However, studies indicate that the bacteria may not survive in sufficient numbers when incorporated into dairy products and during their passage through the gastrointestinal tract (Iyer and Kailasapathy, 2005). A technique called microencapsulation is therefore useful for packaging of probiotic cells by prebiotic material gives higher probiotic viability. Microencapsulation has been investigated for improving the viability of microorganisms in both dairy products and the GI tract. Use of alginate for microencapsulation is limited due to its low physical stability in the presence of chelating agent. A cross-linked alginate matrix system at very low $\mathrm{pH}$ is reported to undergo a reduction in alginate molecular weight causing a faster degradation and release of active ingredients (GI). However, coating alginate beads with polycations can improve their chemical and mechanical stability, consequently improving the effectiveness of encapsulation. The coating of alginate beads with polycations has been extensively studied in pharmaceutics and biotechnology (Krasaekoopt et al., 2006; Babu et al., 2011).

The main objective of the present study was to extend the life span of probiotic cells during storage under refrigerated conditions as well as in the gastrointestinal tract of humans and animals using symbiotic double microencapsulation method.

\section{Materials and Methods}

\section{Symbiotic Double Microencapsulation Procedure}

The initial microencapsulation was carried out using the extrusion technique (Krasaekoopt et al., 2006).An 18 h old probiotic LAB culture grown in Sterile de Man Rogosa and Sharpe (MRS) Broth was mixed with $20 \mathrm{ml}$ of $2 \%(\mathrm{w} / \mathrm{v})$ sodium alginate solution containing sterile $1 \%$ corn starch. The cell suspension was injected through a $0.29-\mathrm{mm}$ needle into sterile 0.05 $\mathrm{m} \mathrm{CaCl}_{2}$. The beads were allowed to stand for $30 \mathrm{~min}$ for gelification, and then rinsed 
with and subsequently kept in sterile $0.1 \%$ peptone solution at $4{ }^{\circ} \mathrm{C}$. This was followed by a second encapsulation using chitosan polymer. The washed beads were immersed in a solution of sterile chitosan dissolved in distilled water acidified with of glacial acetic acid ( $\mathrm{pH}$ between 5.7 and 6.0) with gentle shaking at $100 \mathrm{rpm}$ for $40 \mathrm{~min}$ on an orbital shaker for coating. The chitosancoated beads were washed with $0.1 \%$ peptone water and stored at refrigerated temperature in sterile $1 \%$ peptone solution.

\section{Enumeration of the Encapsulated Probiotics or Encapsulation Efficiency}

One gram of the encapsulated beads was incorporated into universal bottle containing $10 \mathrm{ml}$ of the depolymerization solution $(\mathrm{pH}$ $7.1 \pm 0.1$ ) comprising of $0.2 \mathrm{M}$ solutions of $\mathrm{NaH}_{2} \mathrm{PO}_{4}$ and $\mathrm{Na}_{2} \mathrm{HPO}$. After incubation at $37^{\circ} \mathrm{C}$ for $10 \mathrm{~min}$, the encapsulated probiotics were released by vortexing and further diluted to appropriate concentrations and plated on MRS agar as well as MRS agar supplemented with L-cysteine hydrochloride. The plates were incubated anaerobically for $48 \mathrm{~h}$ and the viability of encapsulated probiotics were expressed as $\log \mathrm{cfu} / \mathrm{ml}$.

\section{Evaluation of the Microencapsulation Efficiency of Probiotics}

\section{Determination of Viability of Bacteria on Storage at $4{ }^{\circ} \mathrm{C}$}

The encapsulated and free bacterial cells were separately stored at $4^{\circ} \mathrm{C}$ in a refrigerator, and sampling of each bacterial culture was carried out at a 7 days interval. The samples were mixed individually with $10 \mathrm{ml}$ sterile depolymerization solution and then subjected to cell survival count on MRS agar. Cell counts were calculated from the colonies on MRS agar plates after $48 \mathrm{~h}$ incubation at $37^{\circ} \mathrm{C}$ under anaerobic conditions, and expressed as colony-forming units per $\mathrm{ml}(\mathrm{cfu} / \mathrm{ml})$.

\section{Determination of Viability of Free Cell and Microencapsulated Cells in Simulated Gastric Juice (SGJ) and Simulated Intestinal Juice (SIJ)}

For determining the survival of free cells in simulated gastric juice (SGJ) or simulated small intestinal juice (SSIJ), the cell culture was incubated in MRS broth at $30^{\circ} \mathrm{C}$ for 24 $\mathrm{h}$ followed by centrifugation at $5000 \times \mathrm{g}$ for $10 \mathrm{~min}$ at $4^{\circ} \mathrm{C}$. The cells were then washed in sterile PBS. $1 \mathrm{ml}$ of the washed cell suspension was mixed with $10 \mathrm{ml}$ of simulated gastric as well as intestinal juice. After brief vortexing, the mixture was incubated at $37^{\circ} \mathrm{C}$. Aliquots removed after 30, 60 and $120 \mathrm{~min}$ of incubation were diluted and plated on MRS agar. Survival percentage was calculated according to the formula:

log cfu/g beads after 2 hours exposure to acidic/ intestinal condition $\times 100$

$\log \mathrm{cfu} / \mathrm{g}$ beads initial count

For determining the Survival of encapsulated cells to simulated gastric juice (SGJ) and simulated small intestinal juice $(\mathrm{SSIJ})$, the prepared beads $(1 \mathrm{~g})$ were placed in a tube containing $10 \mathrm{ml}$ of sterile SGJ and SIJ and incubated for $120 \mathrm{~min}$. Aliquots of dissolved beads from each bacterium were removed at time interval of 30, 60, and 120 min respectively and assayed using same procedure as above. The survival percentage was calculated according to the same formula as above.

For determining the Survival of Microencapsulated and free cells after Sequential Incubation in Simulated Gastric and Intestinal Juices, microparticle samples 
(1 g) were added to conical tubes containing $20 \mathrm{ml}$ of SGJ ( $\mathrm{pH} 2.0$ ) and incubated for 180 min. After incubation, the microparticles were separated by a sieve and subsequently placed in $20 \mathrm{ml} \mathrm{SIJ} \mathrm{(} \mathrm{pH} \mathrm{8.0)}$. The tubes were incubated at $37{ }^{\circ} \mathrm{C} / 180 \mathrm{~min}$. Aliquots were removed and assayed by plating suitable dilutions and assayed using same procedure as above. The survival percentage was calculated according to the same formula as above.

\section{Results and Discussion}

Microencapsulation of microorganisms, via tailor-made carriers composed of non-toxic materials, has frequently been used to impart protection against stressful environmental factors.

Coating protects the active content from environmental stresses such as acidity, oxygen and gastric conditions, and can be used, to help the content pass through the stomach. Besides enhancing the viability of bacteria, microencapsulation facilitates handling of cells and allows a controlled dosage.

Protection of probiotics by microencapsulation in alginate capsules is a method of improving their viability in functional foods. Alginate is often used as an encapsulating material because it has the benefits of being non-toxic and being readily available.

Chitosan polymers can further polymerize by means of cross-link formation in the presence of anions and polyanions. In the present study, symbiotic alginate-chitosan double microcapsules of probiotics with their complementary prebiotic, hi-maize corn starch were successfully prepared using extrusion technique.

\section{Encapsulation Efficiency}

In order to survive and reach the colon in quantities large enough to facilitate colonization, a large number of initial cells must be entrapped in the beads. The symbiotic microencapsulated beads were prepared successfully using 'Extrusion Method' using alginate - chitosan as wall material.

The initial cell count before encapsulation was in the range of $12.1235 \log 10 \mathrm{cfu} / \mathrm{ml}$. High cell loading in the range of $10.932 \mathrm{log}$ $10 \mathrm{cfu} / \mathrm{ml}$ was achieved in coated beads. Their encapsulation efficiency was found to be $90.17 \%$. Though, microencapsulation resulted in a 2 log reduction in count as compared to the free cells, the loss in viability was not very high and may have resulted due to manual methods applied during encapsulation.

\section{Estimation of Efficacy between Free Cell and Symbiotically Double Coated Microcapsule Survival at $4^{\circ} \mathrm{C}$}

Microencapsulation of microorganisms, via tailor-made carriers composed of non-toxic materials, has frequently been used to impart protection against stressful environmental factors. This has allowed several types of food products to become effective carriers of sensitive microorganisms. In particular, delivery of active probiotic cells in a microencapsulated form has received increasing attention in recent years as microencapsulation provides a particularly suitable micro-environment in which the bacteria can more easily survive during processing and storage and be released at the appropriate location(s) in the gastrointestinal tract. 
Microencapsulation of various bacterial cultures has been a common practice for expanding their shelf life. As the primary goal of refrigeration is to inactivate the spoilage and pathogenic microorganisms and store a safe product with enhanced shelf life (Kim et al., 2005.), it is inevitable to kill non-pathogenic organisms like probiotics which are supposed to provide health benefits. Therefore, it becomes important to search for a new method to selectively control such organisms under refrigeration conditions. Coating only with alginate does not give good protection during gastric condition. However, coating with chitosan is found to improve the stability of alginate coated beads (Ivanovska et al., 2012).

Several studies have showed that the survival of microencapsulated bacteria was improved in alginate-chitosan microparticles over that of nonencapsulated bacteria during the storage period. In the present study as well, double coated microencapsulated beads were found to provide higher protection during refrigeration. This is probably due to the protection rendered by the thicker membranes with higher molecular weight chitosan.

Here, the initial count of free cells was found to be $12.574 \pm 0.743$, while encapsulated cells showed initial count of $12.0755 \pm 0.466$. Though, the initial count of free cells was not significantly altered after encapsulation, refrigeration for 7 days proved the efficacy of microencapsulation in conferring protection on the probiotics where in comparison with $78.75 \%$ survival as observed for free cells, the encapsulated cells showed $90.29 \%$ survival (Table 1).

\section{Survival of the Symbiotic Microencapsulated Probiotics under Simulated Gastrointestinal Condition}

The basic principle of this methodology involves exposing symbiotic encapsulated and non- encapsulated probiotic cultures to simulated gastrointestinal conditions mimicking the transit of food from a low $\mathrm{pH}$ environment ( about 2) in the stomach to a higher $\mathrm{pH}$ environment (about 8) in the small intestinal tract and monitoring total viable counts of probiotics through each step. The main development of functional food refers to any food article which contains probiotics and prebiotics in combination with a technique involved in the fortification of the bacterial microbiota in the intestine. Therefore, a further attempt was made to evaluate the efficacy of these symbiotic microencapsulated beads under simulated gastrointestinal conditions.

\section{Simulated Gastric Juice (SGJ)}

One of the basic purposes of symbiotic microencapsulation was to offer adequate protection to probiotic microorganisms against harsh acidic condition during stomach transit. The stomach environment ( $\mathrm{pH}$ 2) was simulated using pepsin. The purpose was to observe any enzymatic degradation effect of this environment on the polysaccharide matrix because such degradation would result in easy release of bacterial cells from the capsules and expose them to the artificial gastric fluid.

The results of the study indicated that the free cells alone were not able to tolerate acidic environment as there was a 7- $8 \mathrm{log}$ $\mathrm{cfu} / \mathrm{ml}$ reduction in the number of viable cells as against the symbiotic microencapsulated beads which showed only 3- $4 \log \mathrm{cfu} / \mathrm{ml}$ reduction in number. Thus microencapsulated cells showed 3-4 times higher protection in stomach environment (Table 2).

For encapsulated cells, no growth was observed on plates with samples obtained from the polymer matrix through the $2 \mathrm{~h}$ of 
exposure to SGJ indicating that there were no viable bacteria released from the interpolymer complex in the low $\mathrm{pH}$ environment probably indicative of the fact that these symbiotic microcapsule coated with alginate- chitosan probably did not swell enough in the SGJ to release the organisms. These results were at par with those of many other researchers who developed symbiotic microcapsules using alginate and chitosan. Though the microencapsulated cell survival was found to show a linear decrease in viability over time, at the end of $2 \mathrm{~h}$, the number of viable bacteria was within the recommended limits. International Dairy Federation (IDF) has suggested a minimum of $10^{7}$ live probiotic bacterial cells at the time of consumption per gram of the product in the processed food products for their attributed health benefits. Thus, microencapsulation of Enterococcus faecium $\mathrm{HB}$ strain by extrusion method using alginate as encapsulating material and chitosan as additional coating agent along with calcium chloride for polyelectrolyte complexation seem to have offered significant protection to the probiotic cells from high acidity conditions of the gastric juice. The coating of beads resulted in a reduced pore size in the double layer membrane thus limiting the diffusion of gastric juice into the beads which in turn prevented encapsulated cells from interacting with the gastric juice and thus provided the best protection to the probiotics in simulated gastric juice.

\section{Simulated Intestinal Juice (SIJ)}

The chitosan coating provides the best protection in bile salt solution because ionexchange reaction takes place when beads absorb bile salt. An insoluble complex is formed between chitosan and bile salt in the chitosan- alginate membrane. Therefore the diffusion of bile salt into the beads may be limited. This will protect encapsulated cells from interacting with the bile salt (Krasaekoopt et al., 2006).

In the present study, the free cells showed only $36.78 \%$ survival while encapsulated cell showed $66.76 \%$ survival under the simulated intestinal conditions (Table 3). Using simulated intestinal conditions, a total 8-9 log reductions were observed in the total number of free cells in comparison with 4 $\log$ reductions in the cell count of encapsulated cells thus, indicating the increased stability of encapsulated cells over free cells under simulated intestinal conditions.

There are several reports showing that alginate-chitosan provides protection as well as improving stability and viability. (Iyer and Kailasapathy, 2005; Krasaekoopt et al., 2006). The results of the present study are thus, at par with the earlier reports indicating the efficacy of encapsulation in aiding survival of probiotic cells in comparison with free cells under simulated intestinal conditions.

\section{Sequential Exposure to SGJ and SIJ}

The pre-conditions of a probiotic LAB, besides being mandatory for it to be in the category of GRAS (Generally Recognized as Safe) is that it should also be recognized as having excellent survival in gastric acid and bile salt conditions (Khalil et al., 2007; Setyawardani et al., 2011). 
Table.1 Viability Count (Log $10 \mathrm{Cfu} / \mathrm{Ml})$ and Survival Percentage under Refrigeration Conditions after 7 Days of Incubation

\begin{tabular}{|l|c|c|}
\hline & Free cell & Encapsulated cell \\
\hline $\begin{array}{l}\text { Viable Count after 7 days } \\
\text { of } \\
(\log 10 \mathrm{cfu} / \mathrm{ml})\end{array}$ & $9.903 \pm 0.7517$ & $10.903 \pm 1.0845$ \\
\hline incubation & & \\
\hline
\end{tabular}

Table.2 Viable Count (Log $10 \mathrm{Cfu} / \mathrm{Ml})$ and Survival Percentage of Free and Encapsulated Cells after Exposure to Simulated Gastric Conditions

\begin{tabular}{|l|c|c|c|c|}
\hline \multirow{2}{*}{ Time interval } & \multicolumn{2}{|c|}{ Free cell } & \multicolumn{2}{c|}{ Encapsulated cell } \\
\cline { 2 - 5 } & $\begin{array}{c}\text { Viable count } \\
\left(\mathbf{l o g}_{\mathbf{1 0}} \mathbf{c f u} / \mathbf{m l}\right)\end{array}$ & $\begin{array}{c}\text { Survival } \\
\text { percentage } \\
(\mathbf{\%})\end{array}$ & $\begin{array}{c}\text { Viable count } \\
\left(\mathbf{l o g}_{\mathbf{1 0}} \mathbf{c f u} / \mathbf{m l}\right)\end{array}$ & $\begin{array}{c}\text { Survival } \\
\text { percentage } \\
(\mathbf{\%})\end{array}$ \\
\hline Initial & $12.3979 \pm 0.7274$ & 100 & $12.606 \pm 0.8109$ & 100 \\
\hline After 30 min & $10.672 \pm 0.8071$ & 86.07 & $12.0755 \pm 0.733$ & 95.79 \\
\hline After 60 min & $8.000 \pm 0.3771$ & 64.52 & $11.3979 \pm 0.4600$ & 90.41 \\
\hline After 90 min & $7.4771 \pm 0.5799$ & 60.30 & $9.591 \pm 0.3752$ & 76.08 \\
\hline After 120 min & $5.301 \pm 0.2074$ & 42.75 & $8.243 \pm 0.5531$ & 65.38 \\
\hline
\end{tabular}

Table.3 Viable Count (Log $10 \mathrm{Cfu} / \mathrm{Ml})$ and Survival Percentage of Free and Encapsulated Cells after Exposure to Simulated Intestinal Conditions

\begin{tabular}{|l|c|c|c|c|}
\hline \multirow{2}{*}{ Time interval } & \multicolumn{2}{|c|}{ Free cell } & \multicolumn{2}{c|}{ Encapsulated cell } \\
\cline { 2 - 5 } & $\begin{array}{c}\text { Viable count } \\
\left(\mathbf{l o g}_{\mathbf{1 0}} \mathbf{c f u} / \mathbf{m l}\right)\end{array}$ & $\begin{array}{c}\text { Survival } \\
\text { percentage } \\
(\mathbf{\%})\end{array}$ & $\begin{array}{c}\text { Viable count } \\
\left(\log _{\mathbf{1 0}} \mathbf{c f u} / \mathbf{m l}\right)\end{array}$ & $\begin{array}{c}\text { Survival } \\
\text { percentage } \\
(\mathbf{\%})\end{array}$ \\
\hline Initial & $12.5118 \pm 0.345$ & 100 & $12.1053 \pm 0.5089$ & 100 \\
\hline After 30 min & $10.7781 \pm 0.7158$ & 86.14 & $11.0232 \pm 0.4748$ & 91.06 \\
\hline After 60 min & $8.4548 \pm 0.3348$ & 67.57 & $10.602 \pm 0.4096$ & 87.58 \\
\hline After 90 min & $6.5118 \pm 0.4743$ & 52.04 & $9.171 \pm 0.4600$ & 75.76 \\
\hline After 120 min & $4.602 \pm 0.5254$ & 36.78 & $8.0827 \pm 0.2843$ & 66.76 \\
\hline
\end{tabular}

Table.4 Viable Count (Log $10 \mathrm{Cfu} / \mathrm{Ml})$ and Survival Percentage of Free and Encapsulated Cells after Sequential Exposure to Simulated Gastrointestinal Conditions

\begin{tabular}{|l|c|c|}
\hline & Free cell & Encapsulated cells \\
\hline Initial count $(\log \mathbf{1 0} \mathbf{~ c f u} / \mathbf{m l})$ & $12.507 \pm 0.232$ & $12.875 \pm 0.675$ \\
\hline Viable count $(\log \mathbf{1 0} \mathbf{c f u} / \mathbf{m l})$ & $2.8308 \pm 0.4031$ & $8.8836 \pm 0.6932$ \\
\hline Survival percentage & 22.63 & 68.99 \\
\hline
\end{tabular}


Table.5 Overall Survival Percentage after Exposure to Refrigeration and Simulated Gastrointestinal Conditions

\begin{tabular}{|l|c|c|}
\hline Conditions & $\begin{array}{c}\text { Free cell (survival percentage } \\
\text { \%) }\end{array}$ & $\begin{array}{c}\text { Encapsulated cell (survival } \\
\text { percentage \%) }\end{array}$ \\
\hline Refrigeration at 4 $\mathbf{C}^{\circ}$ & 80.115 & 95.69 \\
\hline Simulated gastric condition & 40.92 & 72.04 \\
\hline Simulated intestinal condition & 30.0 & 73.3 \\
\hline $\begin{array}{l}\text { Sequential exposure to } \\
\text { gastrointestinal condition }\end{array}$ & 22.63 & 68.99 \\
\hline
\end{tabular}

In the present study, both, free unencapsulated probiotic organisms as well as symbiotic microcapsules coated with alginate- chitosan were incubated for total 5 h. under simulated gastrointestinal conditions which included sequential $2 \mathrm{~h}$. incubation in the simulated gastric environment followed by further $3 \mathrm{~h}$. incubation in the simulated intestinal conditions. The general aim of microencapsulation is, firstly, to protect probiotic bacteria in foods and in the passage through the stomach, since free cells usually do not survive in gastric conditions, and secondly, to release the probiotics in their target, the gut. It was observed that during exposure to acidic conditions, the microcapsules remained intact whereas after entering the intestinal environment, bursting of microcapsules began to occur. Microcapsule swelling upon intestinal release may have resulted from pretreatment in stomach conditions which must have interfered with the cross-linking, in turn weakening it and on further exposure to the alkaline intestinal conditions have finally led to the bursting of microcapsules.

After the total sequential exposure to simulated gastrointestinal conditions, free unencapsulated probiotic organisms showed a total of $10 \mathrm{log}$ reductions, which is more than that observed after individual exposures to gastric or intestinal conditions respectively. In case of encapsulated cells, a total $4 \log$ reduction was observed in the cell count which was also higher than that observed after individual exposures. As against the free unencapsulated probiotic organisms, this reduction was just one log higher indicating increased survival of the probiotics on encapsulation. In general, as against $22.63 \%$ survival of free unencapsulated probiotic organisms, which was not good enough to confer health benefits, the encapsulated cells showed $68.99 \%$ survival. Thus encapsulated cells showed approximately 4 times greater survival than free unencapsulated probiotic organisms (Table 4 \& 5).

On the whole, the microcapsules were found to be adept at protecting the encased probiotic cells under simulated gastrointestinal conditions with cell viabilities remaining within the requisite limits proposed by the IDF throughout the 5 h. residence time in the simulated environment.

\section{References}

Babu Govind, Rath Shantanu, Nithyalakshami V. 2011. Probiotic Viability of Freeze Dried Symbiotic Microcapsules in Skim Milk Powder at Ambient Storage Condition. Internet J. Food Safety, 13: 62-68.

Behboud Jafari, Ali Rezaie, Siamak Alizadeh. 2011. Isolation and Identification of potentially probiotic bacteria from Traditional Dairy 
Products of Ardabil region in Iran Ann.

Biol. Res., 2 (6): 311-317.

Hyun-jue Kim, Han-seung Shin, Woel-kyu

Ha, Hee-jin Yang, Soo-won Lee. 2005.

Characterization of Lactic Bacterial

Strains Isolated from Raw Milk. Ajas, 131-136.

Iyer, C., Kailasapathy, K. 2005. Effect of Co-encapsulation of Probiotics with Prebiotics on Increasing the Viability of Encapsulated Bacteria under In Vitro Acidic and Bile Salt Conditions and in Yogurt. J. Food Sci., 70(1).

Kailasapathy Kaila, Chin James. 2000. Survival and therapeutic potential of probiotic organisms with reference to Lactobacillus acidophilus and Bifidobacterium spp. Immunol. Cell Biol., 78: 80-88.

Kosin Bussarin, Rakshit Sudip Kumar. 2006. Microbial and Processing Criteria for Production of Probiotics: A Review. Food Technol. Biotechnol. ,44(3): 371379.

Krasaekoopt Wunwisa, Bhandari Bhesh, Deeth Hilton, C. 2006. Survival of probiotics encapsulated in chitosancoated alginate beads in yoghurt from UHT- and conventionally treated milk during storage. $L W T, 39: 177-183$.

Lapsiri Wanticha, Nitisinprasert Sunee, Wanchaitanawong Penkhae. 2011. Lactobacillus plantarum Strains from Fermented Vegetables as Potential
Probiotics. Kasetsart J. Nat. Sci., 45: 1071-1082.

Ashraf, M., Arshad, M., Siddique, M., Muhammad, G. 2009. In vitro screening of locally isolated Lactobacillus species for probiotic properties, Pakistan Vet. J., 29(4): 186190.

Michael de Vrese. 2009. Health benefits of probiotics and prebiotics in women. Menopause Int., 15: 35-40.

Rowaida Khalil, Hoda Mahrous, Khalil ElHalafawy, Kamal Kamaly, Josef Frank, Morsi El Soda. 2007. Evaluation of the probiotic potential of lactic acid bacteria isolated from faeces of breastfed infants in Egypt. African $J$. Biotechnol., 6(7): 939-949.

Setyawardani, T., Rahayu, W.P., Maheswari, R., Palupi, N.H.S. 2011. Identification and Characterization of Probiotic Lactic Acid Bacteria Isolated from Indigenous Goat Milk. Ani. Production, 13(1): 57-63.

Tanja Petreska Ivanovska, Lidija Petruševska-Tozi, Margita Dabevska Kostoska, Nikola Geškovski, Anita Grozdanov, Chris Stain, Trajče Stafilov, Kristina Mladenovska. 2012. Microencapsulation of Lactobacillus casei in chitosan-ca- alginate microparticles using spray-drying method. Macedonian J. Chem. Chemical Engi., 31(1): 115-123.

\section{How to cite this article:}

Shilpa Sabnis and Nikita Malavkar. 2016. Development of Symbiotic Double Microencapsulation Technique for Efficient Delivery of Probiotics. Int.J.Curr.Microbiol.App.Sci. 5(4): 306-314. doi: http://dx.doi.org/10.20546/ijcmas.2016.504.036 